\title{
Relato da experiência do trabalho com jogos manuais de raciocínio lógico como reforço para as disciplinas de algoritmos e linguagem de programação
}

\author{
Roberto Pires Silveira ${ }^{1}$, Sônia Alcântara ${ }^{2}$ \\ roberto.silveiradifrj.edu.br, sonia.alcantara@ifrj.edu.br
}

\section{Resumo}

Este artigo relata a experiência vivenciada, pelos alunos do Curso Técnico em Informática pelo projeto PRONATEC no Campus Nilo Peçanha do Instituto Federal de Educação, Ciência e Tecnologia do Rio de Janeiro, durante a oficina de jogos manuais de raciocínio lógico que objetivou reforçar os conceitos trabalhados nas disciplinas de algoritmos e linguagem de programação e a melhoria do desempenho dos alunos nestas disciplinas após a finalização da experiência.

Palavras chave: Raciocínio lógico, jogos manuais, algoritmos.

\begin{abstract}
This article reports the real experience of the students of the Computing Technical Course projected by PRONATEC program in Campus Nilo Peçanha of Federal Institute of Education, Science and Technology of Rio de Janeiro, during the workshop of logical manuals games of reasoning aimed to reinforce the concepts worked in the algorithms and programming disciplines, and improving the performance of students in these disciplines after completion of the experiment.
\end{abstract}

Keywords: Logical Reasoning, manuals games, algorithms.

${ }^{1}$ - Licenciado em Computação, Especialista em Redes de Computadores, Mestre em Materiais, Professor do Instituto Federal de Educação, Ciência e Tecnologia do Rio de Janeiro

2 - Pedagoga, Psicopedagoga, Mestre em Educação, Pedagoga do Instituto Federal de Educação, Ciência e Tecnologia do Rio de Janeiro 


\section{Introdução}

Historicamente, alunos de cursos de tecnologia da informação, de nível técnico ou superior, apresentam grande dificuldade de assimilação de conceitos no primeiro contato com o conteúdo de lógica de programação. Estudos revelam um elevado índice de abandono dos cursos de TI (Tecnologia da Informação) quando chegam ao momento de analisar e desenvolver códigos de programação por conta da complexidade [Castro, 2003] ou por conta da constante adoção do modelo de "ensino tradicional" apontado por Borges (2000). Para amenizar essa situação, projetos estão sendo desenvolvidos com crianças no segmento de desenvolvimento de jogos, que buscam despertar o interesse dos educandos através do contexto.

Os jogos podem ser ferramentas eficientes, pois eles divertem enquanto motivam, facilitam o aprendizado e aumentam a capacidade de retenção do que é ensinado, exercitando as funções mentais e intelectuais do jogador [Tarouco, 2005].

De acordo com Johnson (2005), os jogos forçam o aluno a decidir, a escolher, a priorizar e que todos os benefícios intelectuais do jogo resultam dessa virtude fundamental, porque aprender como pensar, em última análise, tem a ver com o aprender a longo prazo e, então, decidir. Johnson ainda compara a maneira como os jogadores pensam com a forma como os programadores pensam quando escrevem um código: uma série de instruções aninhadas com múltiplas camadas.

Os jogos constituem um poderoso recurso de estimulação do desenvolvimento integral do educando. Eles desenvolvem a atenção, disciplina, autocontrole, respeito às regras e habilidades perceptivas e motoras relativas a cada tipo de jogo oferecido [Rizzo, 1996]. Por detrás do aparente “jogar” observa-se o processo de interação, descrito por Piaget (1983) entre o sujeito e o objeto (o próprio problema), em que o sujeito adapta suas ações de acordo com a resposta observada no objeto.

A inclusão do elemento lúdico no aprendizado proporciona ao indivíduo a capacidade de interagir com o mundo em sua volta. Silva (2008) diz que é preciso criar condições para a formação de indivíduos capazes de agir sobre o mundo e transformálo. Assim, utilizar um jogo para auxiliar no ensino de algoritmos e programação parece uma decisão bastante indicada e um tanto quanto inovadora, até pela complexidade dessas disciplinas. 


\section{Metodologia}

Identificou-se, a partir de uma reunião pedagógica no IFRJ - Campus Nilo Peçanha, uma dificuldade no processo de ensino-aprendizagem com os alunos do primeiro módulo do Curso Técnico em Informática vinculado ao programa PRONATEC nas disciplinas de Algoritmos e Linguagem de Programação por conta do baixo rendimento nas avaliações teóricas a que os alunos foram submetidos.

As disciplinas que trabalham com a lógica de programação são a base para o aprendizado das linguagens de programação, pois consistem na capacidade de analisar e resolver problemas através da construção de códigos em algoritmos [Rapkiewicz, 2006].

Durante o processo de ensino de algoritmos e programação notou-se que grande parte dos alunos apresentava dificuldades em assimilar as abstrações envolvidas em conceitos como estruturas de tomada de decisão, de repetição, de alocação estática de dados, entre outros, não conseguindo desenvolver o raciocínio lógico necessário para a resolução de exercícios diversos. Na literatura podemos encontrar vários problemas e dificuldades relacionados à disciplina de algoritmos em cursos técnicos e superior. Entre esses problemas destacam-se os aspectos de motivação e de desenvolvimento de raciocínio lógico, em que os alunos encontram grande dificuldade de adaptação quando estão acostumados a decorar o conteúdo ao invés de criar soluções [Pereira e Rapkiewicz, 2004] [Rodrigues, 2002].

$\mathrm{Na}$ tentativa de amenizar essas dificuldades identificadas pela equipe pedagógica, criou-se a oficina de jogos manuais de raciocínio lógico baseada na metodologia da computação desplugada. Essa metodologia possibilita que os conceitos computacionais sejam transmitidos de forma simples e interativa para os estudantes, sem a necessidade de hardware e/ou software especializados [Bell e Witten, 1995].

Os jogos trabalhados na oficina foram: torre de hanói, blackjack, xadrez, damas, purrinha, entre outros. Cada oficina tinha a duração de aproximadamente uma hora e tinham periodicidade semanal. Em cada encontro era explorado um jogo, em que o grande desafio consistia em compreender as regras e desenvolver o jogo, oportunizando a todos a participação e por fim relacionar aos conteúdos das disciplinas técnicas anteriormente citadas. 
Durante o trabalho com cada jogo, foram expostas as regras e técnicas do jogo que imediatamente foram identificadas e correlacionadas pelos alunos com conceitos abordados na disciplina de algoritmos. Durante o trabalho com a Torre de Hanói, por exemplo; jogo que consiste em passar anéis de um lado ao outro de um tabuleiro de três pinos, obedecendo às regras de remover um anel por vez e não colocar um anel maior por cima de um anel menor; os alunos perceberam a semelhança dos objetivos e técnicas do jogo com os conceitos de funções recursivas, estruturas aninhadas, algoritmos para resolução de fibonacci, cálculo de fatorial, entre outros.

\section{Resultados obtidos}

Ao final do trabalho realizado com a oficina de jogos manuais de raciocínio lógico, foi possível observar significativa melhora de rendimento e desempenho por parte dos alunos na disciplina de Algoritmos como mostram os gráficos a seguir:

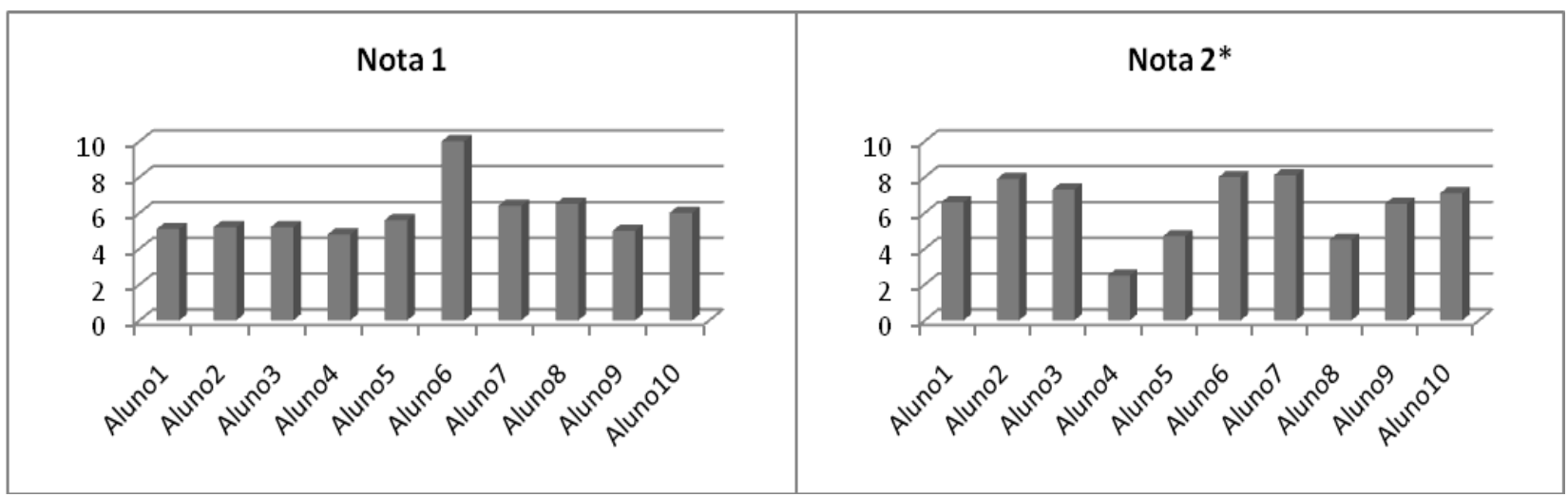

Gráfico 1 - Desempenho antes da oficina

Gráfico 2 - Desempenho depois da oficina

O Gráfico 1 representa as notas dos alunos no primeiro bimestre do módulo e o Gráfico 2 representa as notas no segundo bimestre, após o trabalho da oficina de jogos. Nota-se melhora no desempenho de $60 \%$ dos alunos e aumento da média da turma de 5,9 para 6,3. Considerando que o aluno 4 desistiu do curso e que o aluno 6 já tinha a nota máxima, sendo impossível haver melhoria, assume-se significativo o aumento de rendimento.

Além da evidente melhora nos resultados das disciplinas, foi possível identificar uma mudança de postura e auto-estima dos alunos, que se mostraram mais capazes de resolver problemas de forma criativa e independente. 
Embora a melhora observada não possa ser atribuída apenas à participação na oficina, infere-se que esta tenha contribuído significativamente, já que estudantes de outras turmas não apresentaram a referida melhora. Outro ganho observado foi a integração da turma, não só após, como também durante a realização dos encontros.

Longe de esgotar-se, tal investigação constitui-se em ponto de partida para aprofundamentos e novas abordagens, pois lançar novos olhares às possibilidades que os jogos oferecem à promoção da aprendizagem é um caminho instigante e desafiador.

\section{Referências}

BELL, T.C.G., Witten, I. (1995).“Computer Science Unplugged: Capturing the interest of the uninterested”. Anais do NZ Computer Conference, Wellington, Nova Zelândia.

BORGES, M. (2000). Avaliação de uma metodologia alternativa para a aprendizagem de programação. VIII Workshop de Educação em Computação - WEI 2000. Curitiba.

CASTRO, T.H.C., Castro Júnior, A.B., Menezes, C.S., Boeres, M.C.S., Rauber, M.C.P.V. (2003) "Utilizando Programação Funcional em Disciplinas Introdutórias de Computação". XI Workshop de Educação em Computação-WEI. Campinas, SP, Brasil.

JOHNSON, S., (2005). Surpreendente!: a televisão e o videogame nos tornam mais inteligentes. RJ: Elsevier.

PEREIRA JR, J. C. R. E RAPKIEWICZ, C. E., (2004). O Processo de Ensino e Aprendizagem de Algoritmos e Programação: Uma Visão Crítica da Literatura. WEIMIG

PIAGET, J., (1983). A epistemologia genética: sabedoria e ilusões da filosofia, problemas de psicologia genética. São Paulo, Abril Cultural.

RAPKIEWICZ, C. (2006). Estratégias pedagógicas no ensino de algoritmos e programação associadas ao uso de jogos educacionais. CINTED-UFRGS: Novas Tecnologias na Educação, RS.

RIZZO, G. (1996). "Jogos inteligentes: a construção do raciocínio na escola natural". Rio de Janeiro: Bertrand Brasil.

RODRIGUES JUNIOR, M. C., (2002). Como Ensinar Programação? Informática Boletim Informativo Ano I $n^{\circ}$ 01, ULBRA, Canoas, RS.

SILVA, F. M.; COSTA, F. P. D.; SANTOS, C. L. (2008). Concepção e realização de um jogo educativo no contexto da aprendizagem colaborativa. Belo Horizonte: SBGames.

TAROUCO, L., 2005. Jogos educativos via WWW, Disponível em: $<$ http://penta3.ufrgs.br/animacoes/JogosEducacionais> Acesso em 06 ago. 2013. 